\title{
Infrared thermograph image analysis for the identification of masonry coatings in historic buildings, in relation to several samples prepared as patterns
}

\author{
L. Palaia ${ }^{1}$, J. Monfort ${ }^{4}$, P. Navarro ${ }^{3}$, R. Sánchez ${ }^{2}$, L. Gil ${ }^{1}$, \\ A. Álvarez ${ }^{1}$, V. López ${ }^{1} \&$ S. Tormo ${ }^{1}$ \\ ${ }^{1}$ Architectonic Construction Department, \\ Polytechnic University of Valencia, Spain \\ ${ }^{2}$ Applied Physics Department, Polytechnic University of Valencia, Spain \\ ${ }^{3}$ Chair Professor in Graphic Expression in Architecture, \\ Polytechnic University of Valencia, Spain \\ ${ }^{4}$ Chair Professor in Structures, Polytechnic University of Valencia, Spain
}

\begin{abstract}
The application of non-destructive methods for architectural heritage knowledge is of extreme importance, in order to avoid producing irreparable damage. The methods to gain this knowledge should be complementary to other types of studies and tests, to make the approach to the building easier. The detection of previous openings of doors and windows, walls that have been demolished and later disguised under the mortar coatings, allows interpretation to act in those points if necessary, without affecting the conservation of the original coatings that the building presents. It is possible to arrive at this aim by using infrared thermography (IRT), as this research group has applied it successfully in some historic buildings. Some samples have been prepared in the laboratory, consisting of bricks coated with different types of mortars hiding iron plates. Later, IRT images of these samples were captured. These images were compared with those IRT images captured of the facades of an existing building. Conclusions were reached from this experience that could be extended to other situations.
\end{abstract}

Keywords: infrared thermography, façade coatings analysis, non-destructive diagnosis, historic buildings. 


\section{Introduction}

The evaluation of historic buildings on site using destructive techniques is against the proper sense of conservation purposes. The development of nondestructive techniques should be considered fundamental. Infrared thermography (IRT) is applied for non-destructive evaluation in many fields. One of these is the surveying of ancient buildings [1-3], producing no damage to the existing constructive elements. The research developed shows that this method could be used as a non-destructive approach to building surveying [4, 5].

As Maldague [6] says, each NDE technique has its own strengths and weaknesses, but in the case of thermography the strengths are a fast inspection rate, no contact being established with the building inspected; security, as no harmful radiation is involved, and relatively easy to interpret results (image format). However, it is also important to consider the effects of thermal losses (convective, radiative, conductive) perturbating thermal contrasts; the cost of the equipment (basically of the IRT camera), and the possibility that this technique enables one to detect only subsurface defects resulting in a measurable change of thermal properties.

As said above, the technique consists of the measurement of radiated electromagnetic energy emitted by a surface at its temperature. It is called the spectral radiance and is defined by Planck's law.

Infrared thermographic images are determined by the emitted radiation of a solid at a determined temperature, by surface unity and time; this value is given by the expression of Stefan-Boltzman [7]

$$
E(T)=\varepsilon(T) \sigma T^{4}
$$

where $T$ is the absolute temperature of the solid, $\sigma$ is the constant StefanBoltzman, independent of the solid material and its temperature $T$, and $\varepsilon$ is the material's emissivity. Its value is 0 and 1 , being 1 when it refers to a solid with the maximum emissive capacity, the so-called black body.

Emissivity also depends on the temperature, though in determined temperature ranges it may be considered as a constant value for the great majority of solids. This is the case of the building materials generally used in construction. So, as an example, it may be considered that building materials do not suffer significant variations in their emissivity in the interval of temperature belonging to ambient variations; it also may be considered that the emissivity of major building materials is situated between 0.7-0.9 (except metallic materials, with the emissivity being lower than these values).

When analysing an IRT image applied to the assessment of an architectonic surface, two aspects should be considered: the temperature and the emissivity. For that reason, a qualitative IRT analysis, based on the intensity of the images produced by differences between radiated emissions by architectonic elements situated close to the surface, must be done considering that the variations showed in the image may be produced by a difference in the emissivity or by a difference in temperature. Obviously, these differences could only be detected between building elements of a different nature in the same surface. 
The different temperature of a building element and any point adjacent to it will be determined, basically, by its mass, its specific heat or thermal conductivity, magnitudes that may produce a substantial variation in its thermal inertia in respect to its adjacent points. This different thermal inertia will produce variable differences of temperature between this element and its surrounding area, in the heating and cooling processes of the building façade. For this reason, a façade assessment requires the analysis of several IRT images obtained at different moments of the heating or cooling processes.

\section{Historic buildings survey}

Historic buildings should be preserved from destruction. They need to be conserved, maintained, repaired or restored. This means that no damage must be introduced to the buildings during their assessment. On many occasions, some prospecting works are done to gather information about the building materials, the previous layout and structural organization. It is convenient to reduce these prospecting works in a way that would mean some sort of destruction of the original elements. IRT images can be used in this sense.

\section{Previous experiences}

The first approaches with the IR thermocamera gave interesting results for the detection of building material discontinuity under the façade coatings.

This device was able to capture images of the building walls, presenting thermal images showing lintel elements as in Figures 1 and 2, also previous repairs and the signals of demolished walls on the existing ones, as in Figures 3 and 4. A previous window that had been walled up was also identified, as in Figures 4-6.

A medieval tower was surveyed by means of IRT images, with promissory results, so the research group aimed to improve the applied method. In this tower, located at Torrent village, close to Valencia City [7], different IRT images were captured in the same day, at different hours, in order to detect the best time

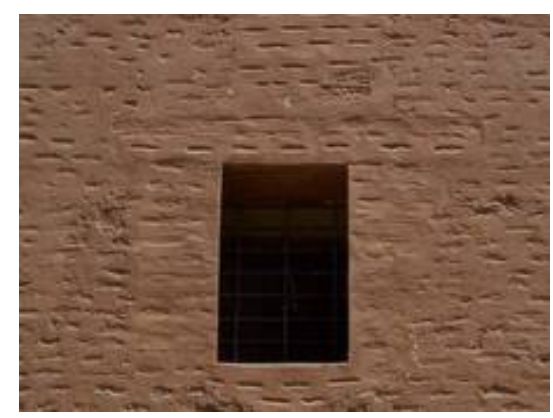

Figure 1: Existing window.

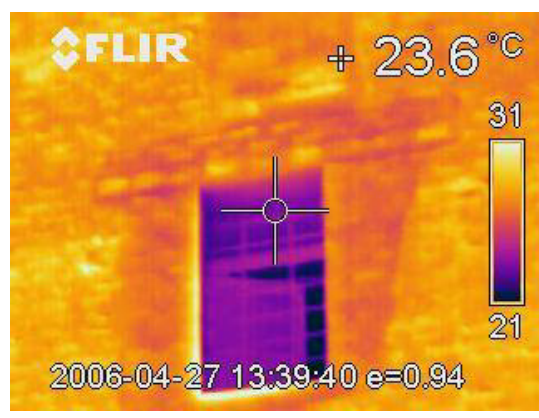

Figure 2: IRT image showing the lintel. 


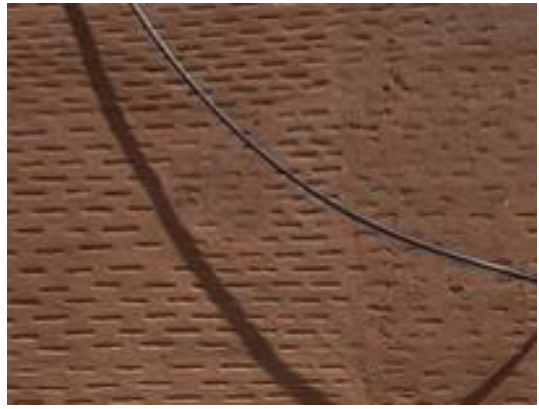

Figure 3: Image of the wall.

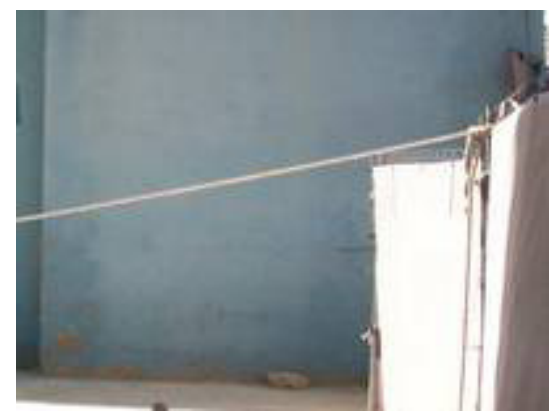

Figure 5: Image of a wall.

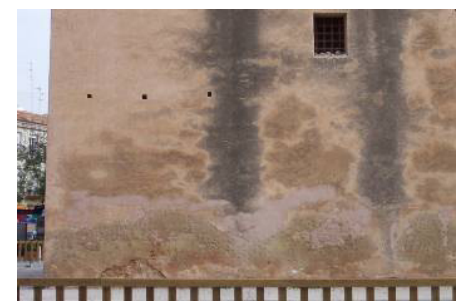

Figure 7: Detail of the tower.

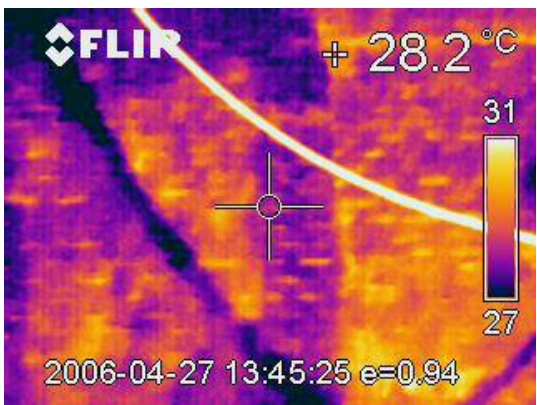

Figure 4: $\quad$ IRT image showing a previous transversal wall, today demolished.

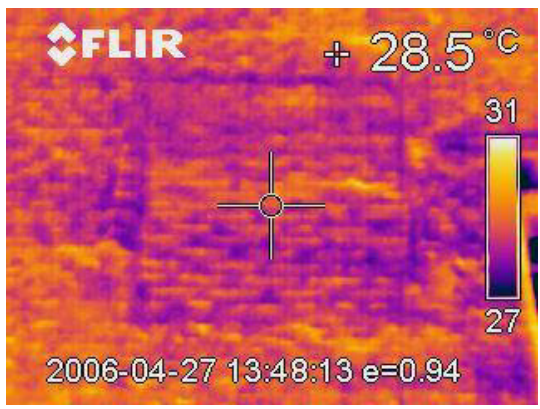

Figure 6: IRT image showing a walled up window.

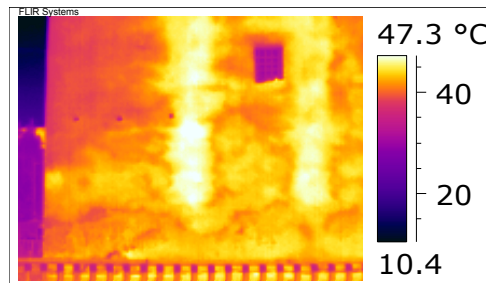

Figure 8: IRT image of the same area, showing a previous opening.

to capture the IRT images. The aspects considered for the IRT images analysis were insulation level, orientation, and wind velocity.

Images were compared, and it was determined that the best hour of the day to take the IRT images was from 20,00 hours onwards, in summer time, when the building materials were cooling down after a sunny day. It was possible to identify walled up hollows and to determine humidity presence. 


\section{Experimental procedures}

As said before, the majority of building materials usually employed in construction have emissive values, situated between the 0.7-0.9 interval. Different mortar coatings have special relevance because of their generalized use in historic building facades.

An IRT analysis of the mortar coatings of historic buildings demands a preliminary study of the emissive behaviour of different mortar types.

For this purpose a comparative study of several mortar types was developed in this research work, in order to value the thermographic appraisal of their possible emissive differences.

The passive infrared thermographic approach was employed using a B2 thermocamera by FLIR System, with field of view $/ \mathrm{min}$ focus distance of $34^{\circ} \mathrm{x}$ $25^{\circ} / 0.1 \mathrm{~m}$ Automatic, thermal sensitivity $<0.10^{\circ} \mathrm{C}$ at $25^{\circ} \mathrm{C}$, a Detector Type Focal plane array (FPA) uncooled micro bolometer and spectral range 7.5 to 13 $\mu \mathrm{m}$. The temperature range of the IRT detector extends from -40 to $+300^{\circ} \mathrm{C}$.

Mortar samples were prepared with the following characteristics: manual bricks, measuring: $22,5 \times 10,8 \times 3,4 \mathrm{~cm}$; wooden frames to provide uniform thickness of mortar coatings, 4,6, 5,5 y 6,5 x $3 \mathrm{~cm}$ (section); iron plates, 30 × 120 x $2 \mathrm{~mm}$; current sand for mortar coatings, cement CEM II-B L 32,5N; gypsum $\mathrm{YG}$, and soaked lime.

Wooden frames and iron plates were arranged as shown in figure 9.

The mortars prepared as samples were: cement mortar, 1:3; lime mortar, 1:3; gypsum mortar, 1:2, with increasing thickness as shown in table 1 .

Iron plates were introduced beneath the mortar coatings in nine of the mortar samples (1 to 9), with the aim of detecting their presence thermographically. The preparation of the samples can be seen in figures 10-15.

The samples exposure to sun radiation is shown in figure 16, and the corresponding IRT images at 16:30 hours are shown in figures 17 and 18 .

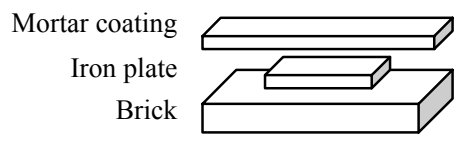

Figure 9: Samples scheme.

Table 1: $\quad$ Samples characteristics.

\begin{tabular}{|l|l|l|l|}
\hline Sample $\mathrm{N}^{\mathrm{o}}$ & Mortar type & Thickness & Iron plate \\
\hline $1,4,7$ & Cement mortar & 1,2 and $3 \mathrm{~cm}$ & yes \\
\hline 10 & Cement mortar & $3 \mathrm{~cm}$ & no \\
\hline $2,5,8$ & Lime mortar & 1,2 and $3 \mathrm{~cm}$ & yes \\
\hline 11 & Lime mortar & $3 \mathrm{~cm}$ & no \\
\hline $3,6,9$ & Gypsum mortar & 1,2 and $3 \mathrm{~cm}$ & yes \\
\hline 12 & Gypsum mortar & $3 \mathrm{~cm}$ & no \\
\hline
\end{tabular}


Samples 1, 4, 7 and 10 were prepared with cement mortar, those numbered 2, 5, 8 and 11 were prepared with lime mortar, and finally, samples 3, 6, 9 and 12 were prepared with gypsum mortar, always varying the thickness: 1,2 and $3 \mathrm{~cm}$. Samples 10, 11 and 12 do not contain iron plates, and have a $3 \mathrm{~cm}$ thick coating.

IRT images were captured at different times: 15:30, 16:30 and 17:30. The obtained results were very expressive.

Firstly we have to mention that the temperature reached by the samples of same thickness is the same. For this reason, the different emissivity must be analysed between samples of the same thickness. It can be seen in the first group

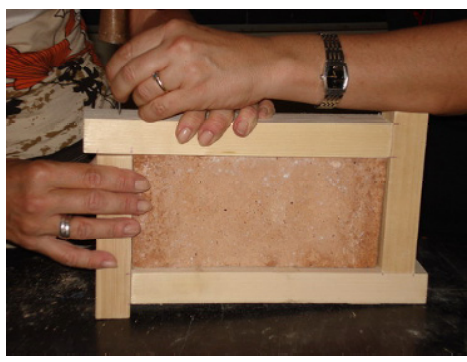

Figure 10: Wooden preparation.

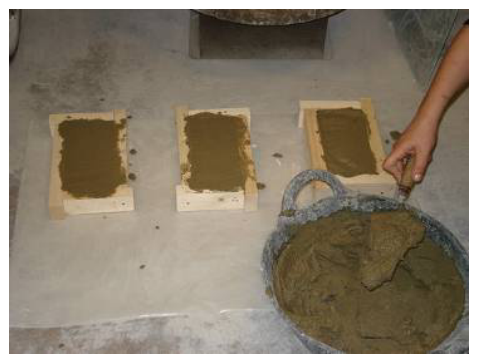

Figure 12: Cement mortar samples.

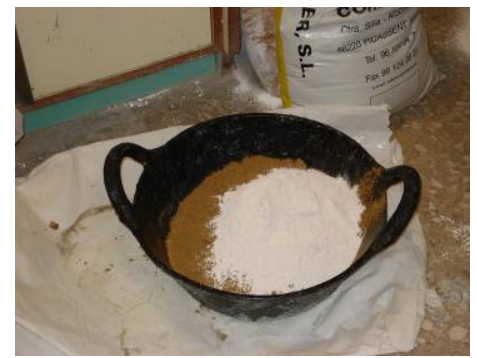

Figure 14: Gypsum mortar

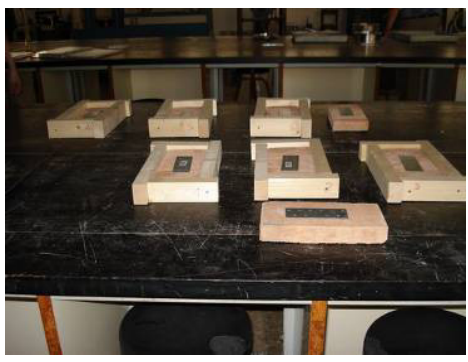

\section{frame Figure 11:}

General view of the samples with the bricks and iron plates presented.

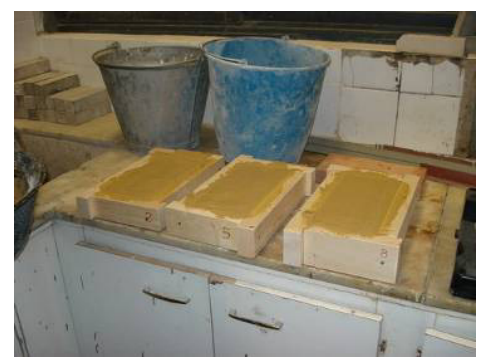

Figure 13: Lime mortar samples.

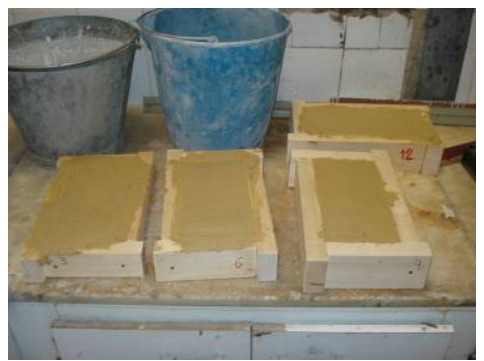

Figure 15: Gypsum mortar samples. preparation. 
of samples, numbered 1 to 3 ; the sample with the higher emissivity is the cement mortar type $\left(n^{\circ} 1\right)$ and the sample with the lesser emissivity is the gypsum mortar type $\left(n^{\circ} 3\right)$. The same behaviour is clearly observed in samples $n^{\circ} 4-6$, where the thickness of the mortar coating is $2 \mathrm{~cm}$. For samples $\mathrm{n}^{\circ} 7-9$ and $10-12$, the differences between emissivity are not detectable.

Considering that all of these six samples are coated with $3 \mathrm{~cm}$ mortar thickness, its temperature is inferior to the first six samples, $n^{\circ} 1-6$, with 1 and 2 cm coating thickness.

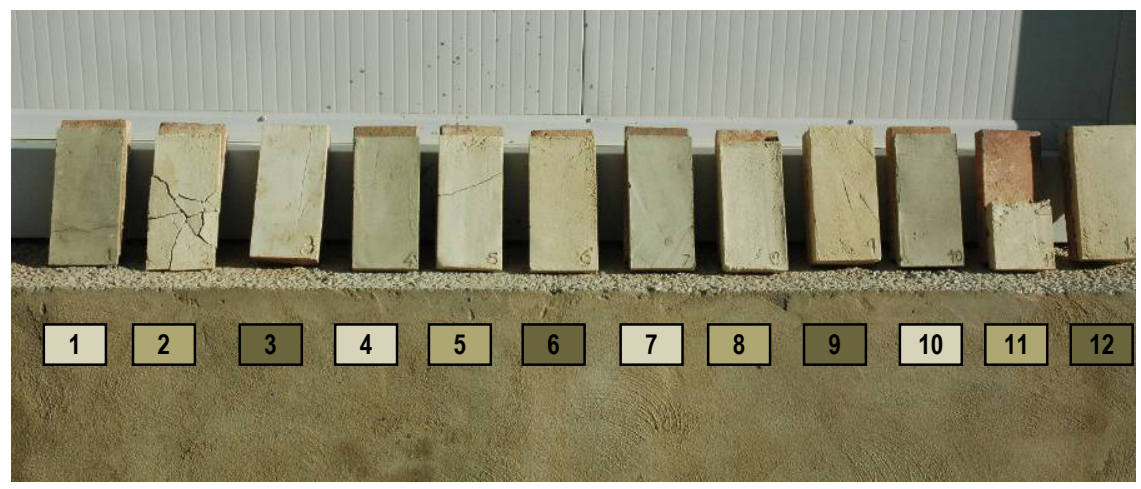

Figure 16: General view of the mortar samples.

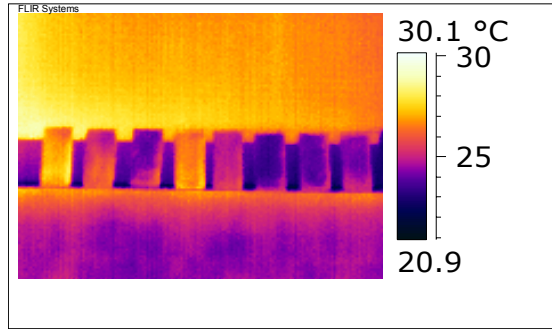

Figure 17: IRT images, samples 1-8.

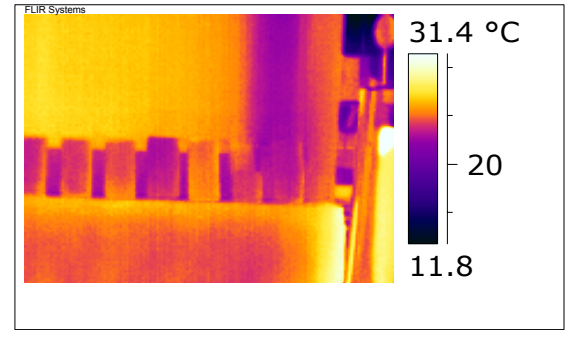

Figure 18: IRT images, samples 6-12.

At this point we can arrive at a very important conclusion of this work: the differences between the emissivity of different coatings of various compositions at the same temperature are clearly identified in an IRT image at a high enough temperature.

Cement mortar coatings present higher emissivity than lime mortar coatings, and these present higher emissivity than those made with gypsum mortar. A clear value where this step is produced cannot be determined.

However, it can be established as a second conclusion that the IRT image of a building façade will be significant if it has reached a minimum temperature with enough uniformity. For this reason, the IRT image should be obtained after the heating process of the surface, and, as said before, in different moments of the cooling down process to evaluate the different thermal inertia effect of its elements. 
It was not possible to identify the iron plates through the thermographic images. It must be considered that the emissive values are measured in conditions of emissivity in radiation in the open air. Therefore, even with the metallic element emissivity being inferior to that of the mortar coating it, the lesser radiation of the iron plate is masked by the emissivity of the mortar covering. This aspect should be developed further, but we may establish an initial hypothesis about it, saying that hidden elements could be detected when they have enough mass with a different specific heat or thermal conductivity, to show a different temperature to their coatings, so a different emissivity from that emitted by their coatings could be seen.

A better approach to this behaviour could be detected when the mortar coatings are applied to a historic building façade. In this way the adjustment to the heating process of the façade was simulated with one of the mortar samples, avoiding the isolated heating effects of the samples previously considered.

The next phase of the research work was to apply the same mortar coverings over the existing walls of an ancient building, located at Picanya (figure 19), which is going to be reused as an administrative centre. It is a free standing building, with orientation to all directions in the four façades, and different construction systems in the walls, such as brick walls, pisè, and masonry work.

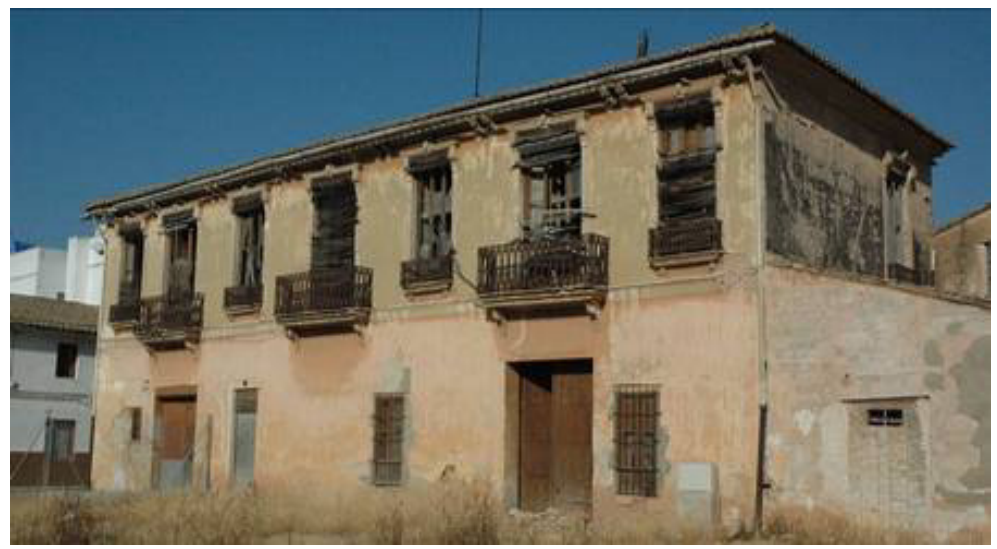

Figure 19: $\quad$ Picanya - historic building. Principal façade (east).

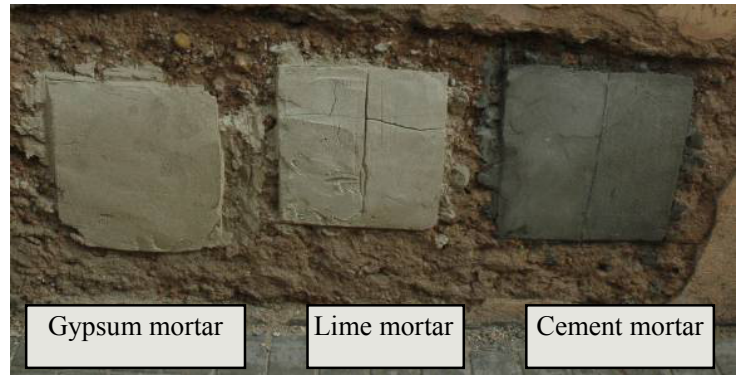

Figure 20: $\quad$ Mortar samples at the south façade. 


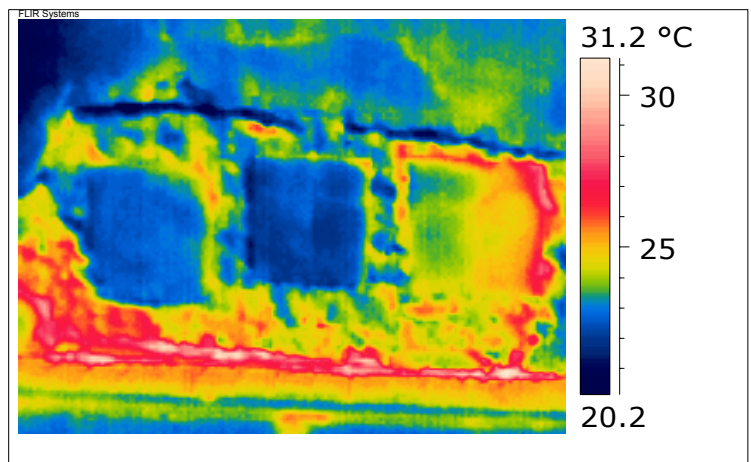

Figure 21: $\quad$ IRT image of the mortar samples at the south façade.

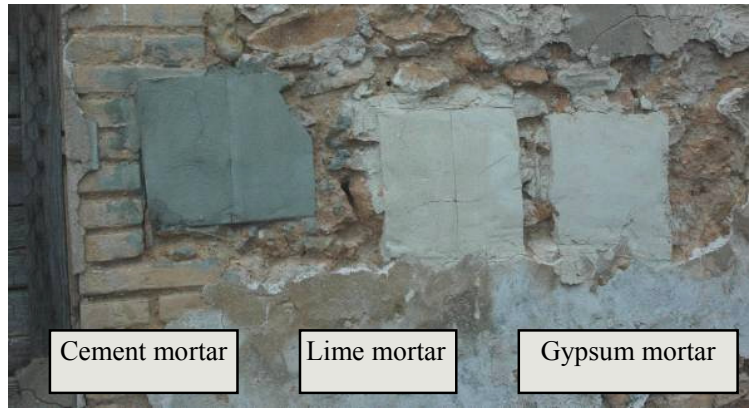

Figure 22: $\quad$ Samples at the west façade.

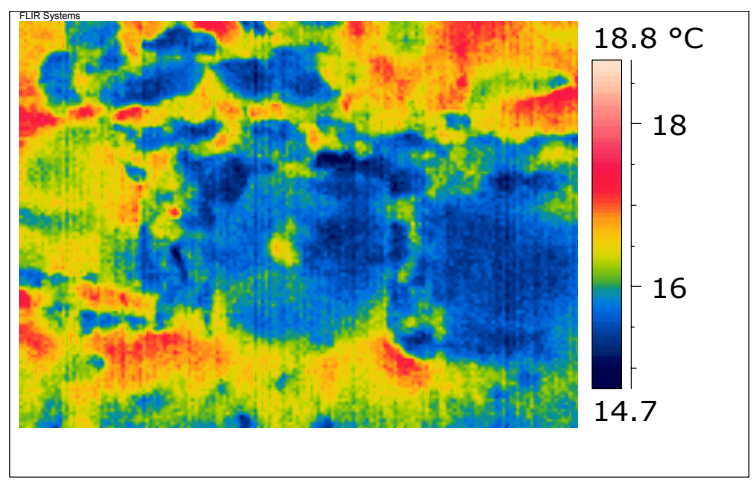

Figure 23: IRT image of the mortar samples at the west façade.

As the wall coatings were deteriorated, we were able to prepare "in situ" samples, $30 \times 30 \mathrm{~cm}, 1 \mathrm{~cm}$ thick, using the same proportions of those prepared in the laboratory. A small coin was introduced at the centre of each sample, in order to detect them with the IRT images. 
The emissive behaviour of the different mortar types can be observed in these ITR images of the samples as before, so that the conclusion established previously can be applied to the mortar coatings applied to the walls. When the building materials present a high emissivity in the same temperature intervals, the different composition can be clearly detected by IRT images.

This work opens an interesting line of research in IRT images of historic buildings analysis based on the comparison of IRT images with qualitative sample images of materials or elements previously studied.

\section{Acknowledgements}

The authors of this paper are professors at the Polytechnic University of Valencia and members of the $\mathrm{I}+\mathrm{D}+\mathrm{i}$ Project financed by the Ministerio de Fomento, 2004 (Spain).

\section{References}

[1] Rosina, E., Using infrared thermography to detect moisture in historic masonry: a case study in Indiana, APT Bulletin, 34.1, 11-, 2003

[2] Sandrolini, F., Franzoni, E., An operative protocol for reliable measurements in porous materials of ancient buildings, Building and environment, 41 (10), 1372-1380, 2006

[3] Schellen, H.L., de Wit, M.H, Heat and moisture modelling of a monumental, massive building, 5th Symposium on Building Physics in the Nordic Countries, Gothenburg, Sweden, 1999

[4] Moropoulou, A., Avdelidis, N.P., Delegou, E.T., Koui, M., Infrared thermography in the evaluation of cleaning interventions on architectural surfaces. Proceedings Inframation 2001, Infrared Training Centre, pp 171175,2001

[5] Moropoulou, A., Delegou, E.T., Avdelidis, N.P., Koui, M., Assessment of cleaning conservation interventions on architectural surfaces using an integrated methodology. Materials Issues in Art and Archaeology VI, edited by P. Vandiveer, M. Goodway, J.R. Druzik and J.L. Mass, Materials Research Society Publications, USA, pp 69-76, 2002

[6] Maldague, X., Theory and practice of infrared technology for nondestructive testing, New York, 2001.

[7] Maldague X., Nondestructive evaluation of materials by infrared thermography, London, Springer-Verlag, 224 p., 1993

[8] Palaia, L.; Sánchez R.; Monfort, J; Gil, L.; Álvarez, Á; Tormo, S.; López, V.; Pérez, C; Navarro, P. Aplicación de la termografía infrarroja a los estudios previos de los edificios históricos, para la identificación de materiales y elementos constructivos ocultos tras los revestimientos, $11^{\circ}$ Congreso Español de NDE, Gijón. 2007. (In submission process) 